BNL-114553-2017-IR

CBETA/018

July 2017

\title{
Descriptions of CBETA magnet tuning wire holders
}

\author{
S. Brooks
}

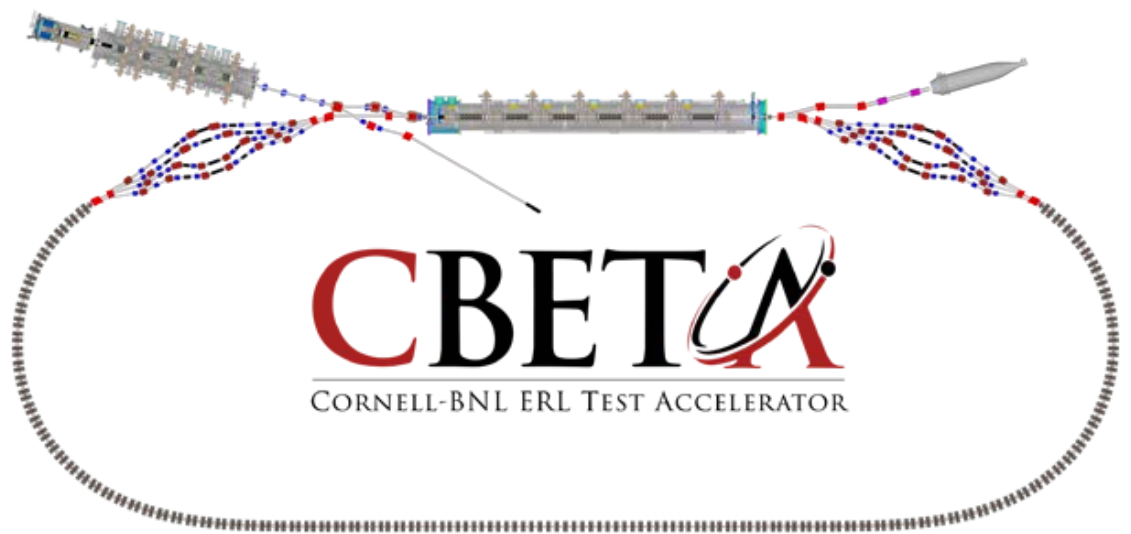

Collider-Accelerator Department, Brookhaven National Laboratory, Upton NY 11973

U.S. Department of Energy

Office of Science, Office of Nuclear Physics

Cornell Laboratory for Accelerator-Based Sciences and Education, Ithaca, NY 14850

Funded by NYSERDA contract 102192

Notice: This document has been authorized by employees of Brookhaven Science Associates, LLC under Contract No. DE-SC0012704 with the U.S. Department of Energy. The United States Government retains a non-exclusive, paid-up, irrevocable, world-wide license to publishor reproduce the published form of this document, or allow others to do so, for United States Government purposes. 


\section{DISCLAIMER}

This report was prepared as an account of work sponsored by an agency of the United States Government. Neither the United States Government nor any agency thereof, nor any of their employees, nor any of their contractors, subcontractors, or their employees, makes any warranty, express or implied, or assumes any legal liability or responsibility for the accuracy, completeness, or any third party's use or the results of such use of any information, apparatus, product, or process disclosed, or represents that its use would not infringe privately owned rights. Reference herein to any specific commercial product, process, or service by trade name, trademark, manufacturer, or otherwise, does not necessarily constitute or imply its endorsement, recommendation, or favoring by the United States Government or any agency thereof or its contractors or subcontractors. The views and opinions of authors expressed herein do not necessarily state or reflect those of the United States Government or any agency thereof. 


\section{Description of CBETA Magnet Tuning Wire Holders}

Stephen Brooks

2017-Jul-19

CBETA machine note \#018

\section{Introduction}

A non-magnetic insert will be placed directly inside the permanent magnet blocks in every CBETA Halbach magnet in order to hold a set of iron "tuning wires". These wires have various lengths around the perimeter of the aperture in order to cancel multipole field errors from the permanent magnet blocks. An example of such a wire holder made of 3D printed plastic is shown below.

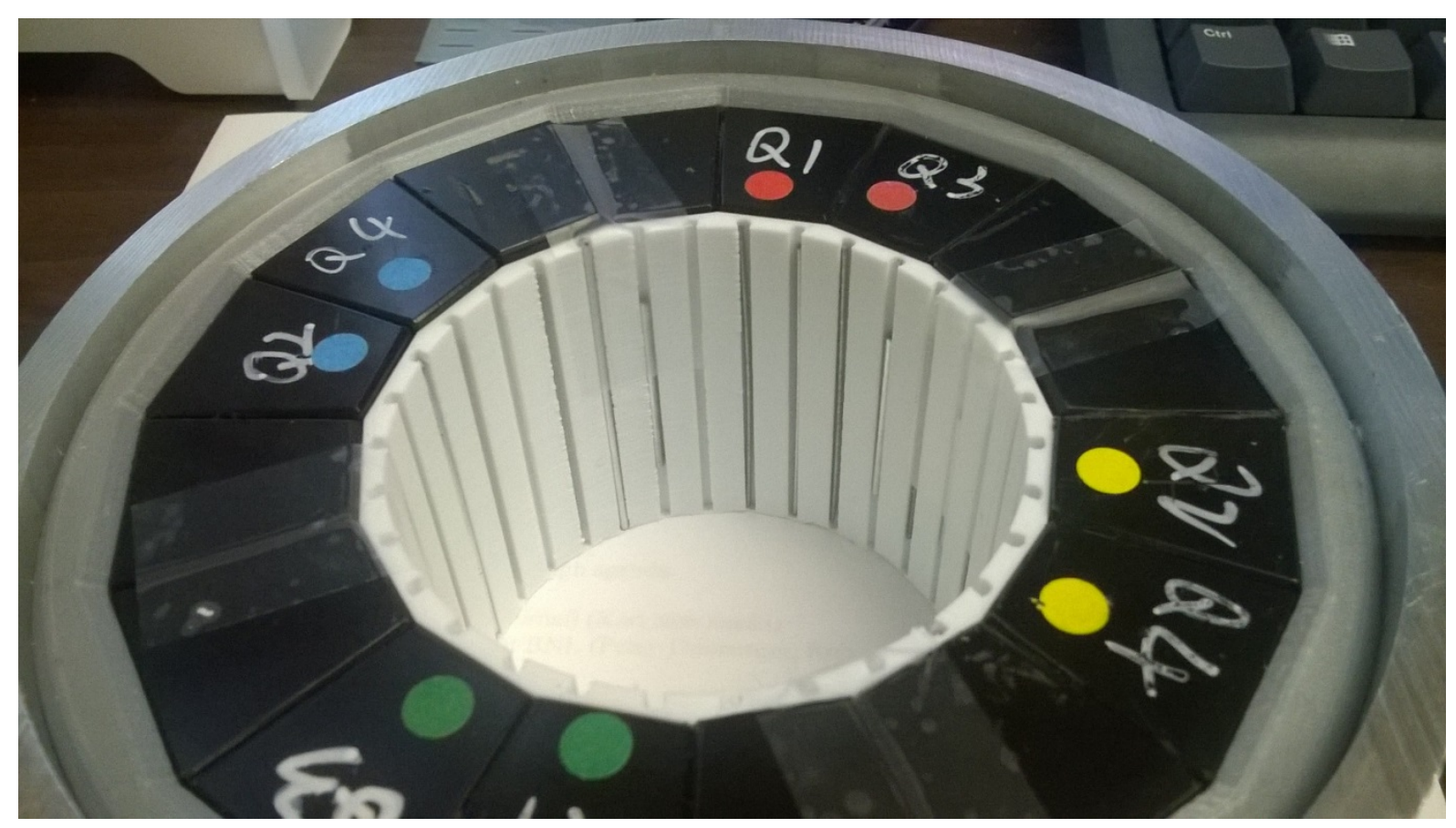

Note that the holder can be made of any non-magnetic material and that the holder pictured above has only 32 slots for wires, fewer than in the final version. The picture below shows a CBETA "first girder" magnet undergoing rotating coil measurement while containing a plastic wire holder. 


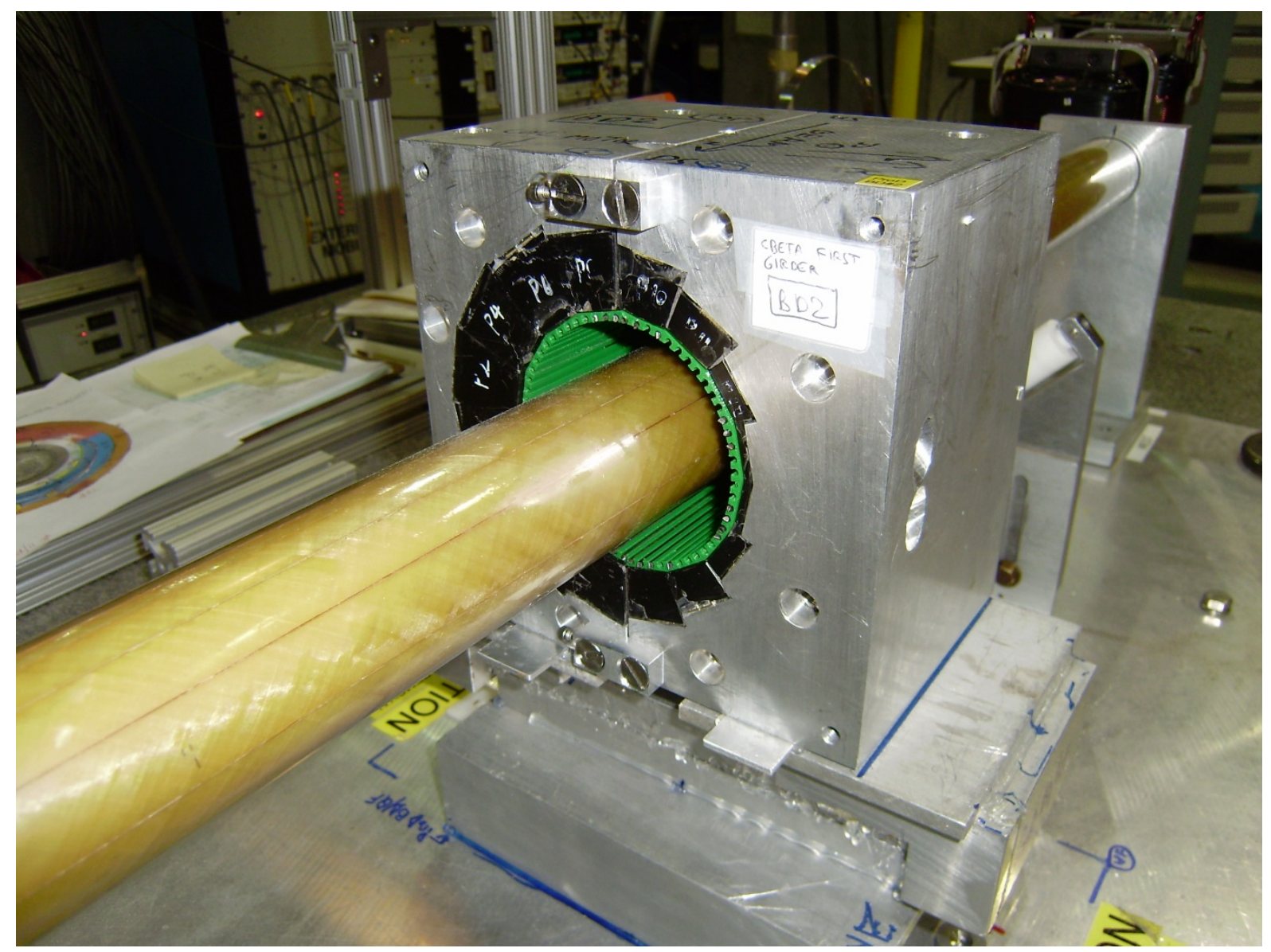

\section{Geometry Description and Dimensions}

The interior of each Halbach magnet is a 16-sided regular polygon in cross-section. The CBETA magnets split into two halves, so the shim holders will be made in halves too (both halves are shown in the 3D model below). Each shim holder half has a large circle removed from the centre of the polygon, which becomes the final usable magnet bore, as well as 64 equal-sized, equally-spaced holes all at the same radius. The holes are offset by half of a gap so a hole does not interfere with the place the two holder halves join. The holes are placed so that the holder is continuous on the outside but the wires can be seen on the inside (this will help with removing wires if needed). However, the holes must be sufficiently indented into the plastic so that the wires do not fall out. 


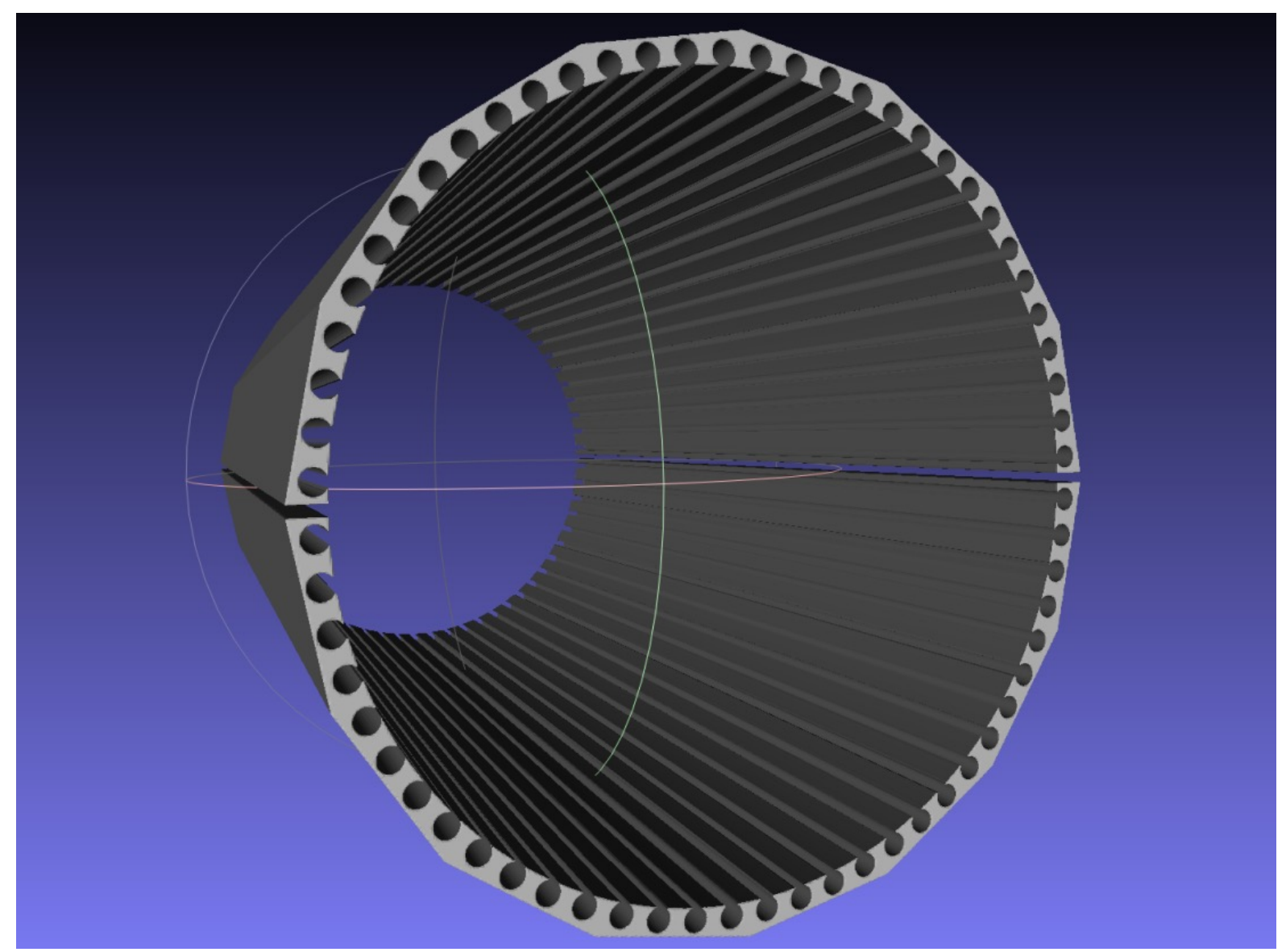

There are two types of Halbach magnet bore in CBETA: 108 QF-type magnets and 108 BD-type magnets. Their dimensions are shown in the table below, consistent with v6/v6.5 of the CBETA Halbach magnet designs.

\begin{tabular}{|l|l|l|}
\hline Parameter & QF-type wire holder & BD-type wire holder \\
\hline Associated magnet types & QF & BD, BDT1, BDT2, QD \\
\hline Magnet length & $133.0 \mathrm{~mm}$ & $122.0 \mathrm{~mm}$ \\
\hline Radius to corner of 16-gon & $\sim 47.105112 \mathrm{~mm}$ & $\sim 44.046339 \mathrm{~mm}$ \\
\hline Radius to side of 16-gon & $46.2 \mathrm{~mm}$ & $43.2 \mathrm{~mm}$ \\
\hline Radius of bore circle removed & $43.3 \mathrm{~mm}$ & $40.3 \mathrm{~mm}$ \\
\hline Radius to centre of wire holes & $44.484 \mathrm{~mm}$ & $41.484 \mathrm{~mm}$ \\
\hline Number of wire circles & 64 & 64 \\
\hline Radius of wire* & $0.080^{\prime \prime}$ & $0.080^{\prime \prime}$ \\
\hline
\end{tabular}

* It is possible a larger radius e.g. 0.105 " may be used depending on magnet quality, which would probably also thicken the holder and reduce the overall bore circle.

\section{Fits}

The shim holder should fit within the magnet bore ideally with a small amount of friction; it can be glued in place once the wires are inserted correctly. For 3D printed plastic, the radius was reduced by $0.2 \mathrm{~mm}$ to account for plastic roughness (3D printer layers) and any magnet construction errors.

The wires should fit within the holes so that they can slide in longitudinally with a small applied force, but ideally with enough friction so that they do not fall out of place if the holder containing 
wires is picked up and turned over. Again, $0.2 \mathrm{~mm}$ was added to the wire radius to give the hole radius in the case of $3 \mathrm{D}$ printed plastic (fast print on Ultimaker 2).

Wires may be glued in place to prevent them moving when the holders are being placed in the magnet (the magnet will strongly attract the wires).

\section{Automated Wire Placement}

The wires may be inserted robotically in the future, in which case the ends of the wire holes facing the robot should be flanged outwards - for instance growing by $1 \mathrm{~mm}$ in radius over $5-10 \mathrm{~mm}$ length - to better guide the wires into the holes. 